\title{
Mitochondrial Complex I Inhibition Accelerates Amyloid Toxicity
}

\author{
Yechan Joh and Won-Seok Choi \\ School of Biological Sciences and Technology, College of Natural Sciences, College of Medicine, \\ Chonnam National University, Gwangju 61186, Korea
}

\begin{abstract}
Alzheimer's disease (AD) is neurodegenerative disease, characterized by the progressive decline of memory, cognitive functions, and changes in personality. The major pathological features in postmortem brains are neurofibrillary tangles and amyloid beta $(\mathrm{A} \beta$ ) deposits. The majority of AD cases are sporadic and age-related. Although AD pathogenesis has not been established, aging and declining mitochondrial function has been associated. Mitochondrial dysfunction has been observed in AD patients' brains and AD mice models, and the mice with a genetic defect in mitochondrial complex I showed enhanced $\mathrm{A} \beta$ level in vivo. To elucidate the role of mitochondrial complex I in AD, we used SH-SY5Y cells transfected with DNA constructs expressing human amyloid precursor protein (APP) or human Swedish APP mutant (APP-swe). The expression of APP-swe increased the level of A $\beta$ protein in comparison with control. When complex I was inhibited by rotenone, the increase of ROS level was remarkably higher in the cells overexpressing APP-swe compared to control. The number of dead cell was significantly increased in APP-swe-expressing cells by complex I inhibition. We suggest that complex I dysfunction accelerate amyloid toxicity and mitochondrial complex I dysfunction in aging may contribute to the pathogenesis of sporadic AD.
\end{abstract}

Key words : Mitochondrial complex I, Rotenone, Alzheimer's disease, APP, A $\beta$, ROS

\section{INTRODUCTION}

Alzheimer's disease (AD) is a progressive and the most common neurodegenerative disease. Though the number of $\mathrm{AD}$ patients has been increasing recently, there is no fundamental cure. $\mathrm{AD}$ is characterized by the impairments of cognitive and memory functions and changes in personality (Selkoe, 1999; Zhang et al., 2011). There are two major pathological features in postmortem brains from patients, which are senile plaques composed of $A \beta$ peptides and neurofibrillary tangles formed of hyperphosphorylated tau (Zhang et al., 2011). Though a small subset of
$\mathrm{AD}$ cases results from an inherited autosomal dominant gene mutation, most cases of $\mathrm{AD}$ are sporadic and agerelated. Cellular, molecular, and pathological mechanisms of disease progression and cell death are not fully understood (Reddy, 2009a). However, aging may play a large role in cell death implicated with $\mathrm{AD}$. Oxidative stress increased steadily by aging leads to the accumulation of oxidized proteins, lipids, and nucleic acids (Smith et al., 1996; Gibson \& Huang, 2002; Mattson \& Liu, 2002; Manczak et al., 2005; Paradies et al., 2010).

$\mathrm{A} \beta$ protein plays a critical role in pathogenesis of $\mathrm{AD}$ (Zhang et al., 2011). Altered metabolism of $A \beta$ leads to the

\footnotetext{
Manuscript received December 19, 2017, Received in revised form December 21, 2017, Accepted December 26, 2017

${ }^{\dagger}$ Corresponding Author : Won-Seok Choi, Ph.D., School of Biological Sciences and Technology, College of Natural Sciences, College of Medicine, Chonnam National University, Gwangju 61186, Korea. Tel: +82-62-530-1912, Fax: +82-62-530-2199, E-mail: choiw@jnu.ac.kr

This is an Open Access article distributed under the terms of the Creative Commons Attribution Non-Commercial License (http:// creativecommons.org/licenses/by-nc/3.0) which permits unrestricted non-commercial use, distribution, and reproduction in any medium, provided the original work is properly cited.
} 
accumulation and the aggregation of $A \beta$ peptides in the brain. A $\beta$ is derived from APP by sequential cleavage. There are two pathways in APP processing, non-amyloidogenic and amyloidogenic pathway (Gandy, 2005; Zhang et al., 2011). In non-amyloidogenic pathway, APP is processed by $\alpha$-secretase and $\gamma$-secretase. Alternatively, $A \beta$ is derived by cleavage of $\beta$-secretase and $\gamma$-secretase. Thus, the access of APP to either $\alpha$ - or $\beta$-secretase seems to regulate $\mathrm{A} \beta$ levels and the pathogenesis of $\mathrm{AD}$ (Gandy, 2005; Zhang et al., 2011). Although the specific mechanisms still remain unknown, $A \beta$ promotes neuronal degeneration by increasing the levels of oxidative stress and disturbing cellular energy metabolism (Gibson \& Huang, 2002; Mattson \& Liu, 2002; Manczak et al., 2005; Querfurth \& LaFerla, 2010). Unlike familial AD overexpressing APP by genetic deficits, enhanced amyloidogenic processing of APP may lead to increase oligomeric A $\beta$ in sporadic AD (Smith et al.. 1996; Haass \& Selkoe, 2007; Querfurth \& LaFerla, 2010).

Since mitochondria is a main source of reactive oxygen species (ROS), its dysfunction can induce complications in ROS processing (Mattson, 2007; Mattson et al., 2008). Increasing number of researches have suggested an association between aging and declining mitochondrial function (Pavlov et al., 2009). Mitochondrial dysfunction has been observed in postmortem brain from AD patients and from AD transgenic mice (Reddy \& Beal, 2008). Several studies on mitochondrial enzymes found decreased levels of cytochrome oxidase, pyruvate dehydrogenase and $\alpha$ ketodehydrogenase in fibroblasts, lymphoblasts and postmortem brains from AD patients (Reddy, 2009b). In addition, free radical production, lipid peroxidation, oxidative DNA damage and oxidative protein damage was increased but ATP production and cell viability was decreased in postmortem AD brains (Parker et al., 1990; Smith et al., 1996; Gibson \& Huang, 2002; Maurer et al., 2002).

Mitochondria could be involved in the mechanism by which intracellular $A \beta$ triggers neuronal toxic pathogenesis
(Eckert et al., 2003). This idea is supported by the reports, in which $A \beta$ is transported into mitochondria and APP derivatives are accumulated within mitochondria in the brains of AD patients (Fernandez-Vizarra et al., 2004; Lustbader et al., 2004; Devi et al., 2006). Taken together, evidences suggest that mitochondrial dysfunction may play a critical role in the pathogenic mechanisms of $\mathrm{A} \beta$ (Eckert et al., 2003; Leuner et al., 2007; Rhein \& Eckert, 2007). However, the mechanism of the mitochondrial complex I contributing to $A \beta$-induced cell death was not fully elucidated.

Here we investigated the role of mitochondria complex I in $\mathrm{A} \beta$ toxicity using human SH-SY5Y cells harboring the AD mutant of APP, wild type APP or control vector and found that inhibition of mitochondrial complex I accelerates pathogenic mechanisms of $A \beta$.

\section{MATERIALS AND METHODS}

\section{Cell culture}

Human neuroblastoma, SH-SY5Y cells were transfected with DNA constructs expressing human wild type APP (APP-WT) or Swedish APP mutant (APP-swe) using Lipofectamine in serum free media as described (Choi et al., 2004). Human wild type and Swedish mutant (K670N, M671L) APP constructs were the generous gift of Dr. I. Mook-Jung (Seoul National University, Korea). Control cells were transfected with empty vector. SH-SY5Y cells were grown in Dulbecco's modified Eagle's medium (DMEM) supplemented with 10\% fetal bovine serum, 100 units $/ \mathrm{mL}$ penicillin and streptomycin at $37^{\circ} \mathrm{C}$ in a humidified incubator containing $5 \% \mathrm{CO}_{2}$. Culture reagents were purchased from Life Technologies (Grand Island, NY).

\section{Drug treatment}

Rotenone was dissolved in DMSO (10 mM) and stored in $-20^{\circ} \mathrm{C}$. Transfected cells were treated with $10-20 \mu \mathrm{M}$ rotenone diluted in DMEM containing $0.5 \%$ fetal bovine 
serum, 100 units/ml penicillin and streptomycin. Rotenone and other reagents was obtained from Sigma-Aldrich (St. Louis, MO, USA)

\section{MTT assay}

SH-SY5Y cells were subcultured in the 24 wells plate. Following stated treatment, cell viability was measured by MTT (3-[4,5-dimethylthiazol-2-yl]-2,5-diphenyltetrazolium bromide) reduction assay as described (Choi et al., 1999). MTT reagent was added to the medium 20-24h after drug treatment. After the incubation for $2 \mathrm{~h}$, the equal amount of MTT extraction solution (20\% SDS in 50\% aqueous dimethylformamide) with media was added and cells were incubated at $37^{\circ} \mathrm{C}$ in $5 \% \mathrm{CO}_{2}$ for overnight. The absorption of the extract was measured at $570 \mathrm{~nm}$ using a microplate reader (Molecular Devices, Sunnyvale, CA).

\section{Detection of reactive oxygen species}

Cells were washed twice with warm saline buffer (144 $\mathrm{mM} \mathrm{NaCl}, 10 \mathrm{mM}$ HEPES, $2 \mathrm{mM} \mathrm{CaCl} 2,1 \mathrm{mM} \mathrm{MgCl} 2,5$ $\mathrm{mM} \mathrm{KCL}$ and $10 \mathrm{mM}$ D-glucose) and incubated with 1 $\mu \mathrm{g} / \mathrm{mL}$ dihydroethidium (freshly made from stock solution, $1 \mathrm{mg} / \mathrm{mL}$ in DMSO) in saline buffer as described previously (Choi et al., 1999). After 15 minutes of incubation at $37^{\circ} \mathrm{C}$ in $5 \% \mathrm{CO}_{2}$, cells were washed twice. Cells were detached and moved in 96 well white plate. Cells were quantitated at Ex535/Em610 (cutoff at $630 \mathrm{~nm}$ ) using fluorescent microplate reader (Molecular Devices, Sunnyvale, CA).

\section{Western blot}

Cells were washed with PBS, harvested and lysed with lysis buffer containing $62.5 \mathrm{mM}$ Tris- $\mathrm{HCl}$ (pH 6.8), 2\% w/v SDS, $10 \%$ glycerol, $50 \mathrm{mM}$ DTT, $0.01 \% \mathrm{w} / \mathrm{v}$ bromophenol blue, $1 \mathrm{mM}$ PMSF and $5 \mu \mathrm{g} / \mathrm{mL}$ a protinin (Choi et al., 2004). Equal amounts of protein were loaded on 10$15 \%$ acrylamide gel and separated by electrophoresis. Samples were transferred onto a PVDF membrane and incu- bated in 5\% skim milk for $1 \mathrm{~h}$. After washing three times with Tris buffered saline with $0.5 \%$ Tween 20 (TBST), membranes were incubated with primary antibodies overnight at $4{ }^{\circ} \mathrm{C}$. Primary antibodies included rabbit polyclonal antibody against A $\beta 1-42$ (1:3000, Merck, Kenilworth, NJ) and mouse monoclonal antibody against $\beta$-actin (Sigma). After washing with TBST, membranes were treated with horseradish peroxidase conjugated secondary antibodies (Merck) for $1 \mathrm{~h}$ at room temperature. The bands were specifically detected by enhanced chemiluminescence (ECL, Merck) reaction.

\section{Propidium lodide staining}

Cells were washed with warm PBS (1M) and incubated with $25 \mu \mathrm{g} / \mathrm{mL}$ propidium iodide in PBS. After 15 minutes, cells were washed twice with PBS. Cells were fixed with 4 $\%$ paraformaldehyde $/ 4 \%$ sucrose in PBS at room temperature for 15 minutes and washed twice with PBS. Cell were stained with DAPI ( $1 \mu \mathrm{g} / \mathrm{mL}$ in PBS) and washed. PI and/ or DAPI stained cells were observed using fluorescent microscope (Leica; Heidelberg, Germany). Cells that were stained positive for PI were counted from five representative fields from each well and scored as dead cells. The ratio of PI positive / DAPI positive cells were presented as cell death rate.

\section{Statistics}

Experimental data were displayed as mean \pm SEM from at least 3 times of experiments. Significance of differences between different groups was analyzed by one-way ANOVA and post-hoc Student's $t$ test. Values of $p<0.05$ were considered as being statistically significant.

\section{RESULTS}

1. APP-swe transfection induces the increase of $A \beta$ levels and rotenone induces loss of cell viability

To confirm the generation of $A \beta$ by APP-swe gene 
transfection, we tested protein levels of A $\beta$. In SH-SY5Y cells, transfection of APP-swe elevated protein level of A $\beta$, specially oligomer forms (Fig. 1A). Equal loading of protein was confirmed by $\beta$-actin level. The expression of wild type APP did not cause the increase of A $\beta$. Consequently, cell viability was decreased by the expression of APP-swe, though the difference was not significant and the overall morphology was not altered within $48 \mathrm{~h}$ of transfection (Fig. 1B, Fig. 1C). We tested the effect of rotenone, complex I inhibitor, to verify the role of mitochondrial inhibition in $\mathrm{A} \beta$ toxicity. Rotenone triggered the morphological changes of treated cells. After $18 \mathrm{~h}$ treatment with rotenone $(20 \mu \mathrm{M})$, a number of cells were detached from surface and their processes were fragmented (Fig. 1B, Fig.
A

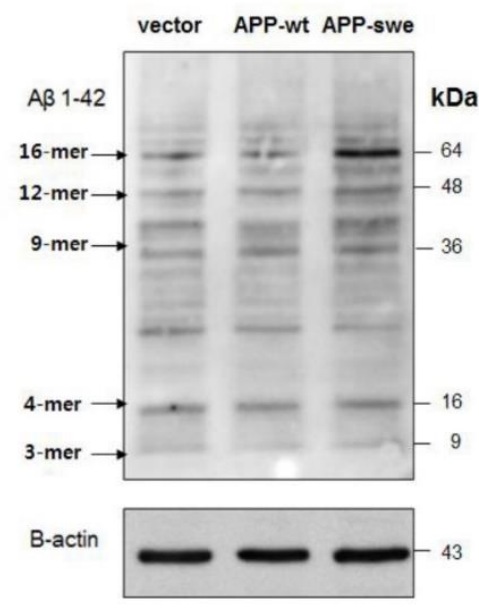

B

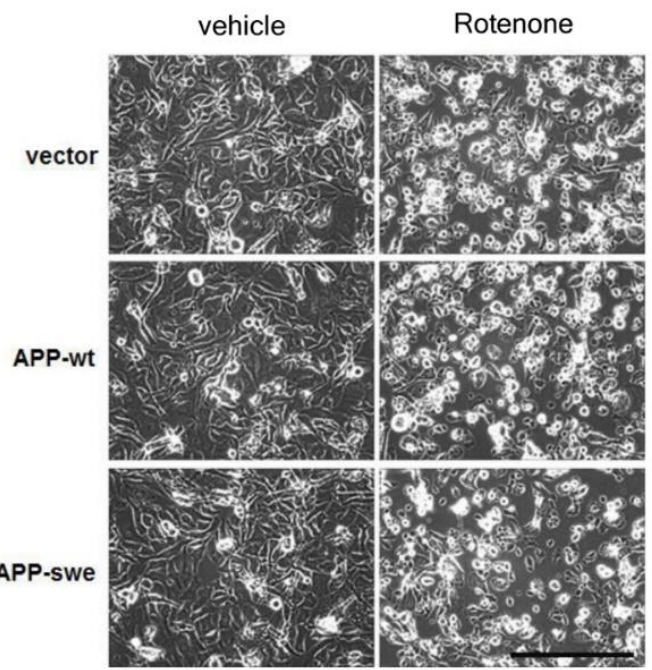

C

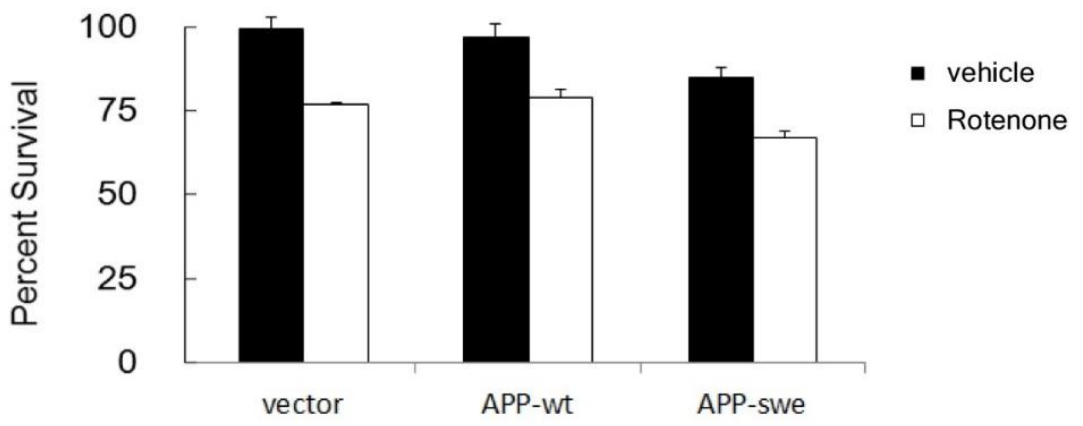

Fig. 1. Increased A $\beta$ protein levels in SH-SY5Y cells expressing APP-swe and the effect of APP-wt or APP-swe expression on rotenone-treated SH-SY5Y cells. A. The A $\beta$ levels of cells transfected with DNA containing swedish mutant APP (APP-swe) were increased in comparison with those of control cells. SH-SY5Y cells were plated in 6 well plate and transfected with DNA containing wildtype APP (APP-wt), APP-swe or control vector. Cells were harvested $48 \mathrm{~h}$ after transfection and $\mathrm{A} \beta$ protein levels were assessed by western blot. $\mathrm{B}$. The morphological changes of SH-SY5Y cells by mitochondrial complex I inhibition. The increase of A $\beta$ levels did not change the morphology of cells (APP-swe). Treatment with rotenone $(20 \mu \mathrm{M})$ for $18 \mathrm{~h}$ triggered the morphological change in cells. Scale bars, $100 \mu \mathrm{m}$. C. After $24 \mathrm{~h}$ treatment with rotenone $(10 \mu \mathrm{M})$, cell viability was decreased. There was no significant difference in rotenone-induced reduction of cell viability among the cells expressing APP-wt, APP-swe or control vector. 
1C). For all three groups of transfected cells, rotenone induced loss of cell viability, however there was no significant difference of the effect of rotenone among three groups of cells (Fig. 1B, Fig. 1C).

\section{Cell death is increased in cells expressing APP-} swe by mitochondrial complex I inhibition

As the difference of the effect of complex I inhibition on cell survival between APP-swe expressing and control cells was not detectable in cell survival assay, we measured cell death rate using propidium iodide (PI) staining. Propidium iodide stains nucleus DNA upon plasma membrane permeabilization which usually occurs in cell death (Lecoeur, 2002). Thus it could be used to identify dead cells. Cells were transfected with either APP-swe or control vector, treated with rotenone $5-10 \mu \mathrm{M}$ for $18 \mathrm{~h}$, and the numbers of dead (PI-positive) cells per total (DAPI-positive) cells were quantified. The ratio of dead cells was increased by either APP-swe transfection or rotenone treatment (Fig. 2). Moreover, when rotenone was treated in cells expressing APP-swe, cell death was significantly accelerated depending on rotenone dose, compared with vector control, suggesting synergistic effect of mitochondrial inhibition and A $\beta$ toxicity on neuronal cell death (Fig. 2).

\section{ROS level is significantly increased by the com-}

\section{bination of $A \beta$ and complex I dysfunction}

Mitochondria is the major hub of cellular energy conversion and major source of ROS generated during the electron transfer process (Gibson \& Huang, 2002; Kushnareva et al., 2002; Leuner et al., 2007; Lustbader et al., 2004; Mattson et al., 2008). The majority of ROS derive from complex I and III and complex I dysfunction is found during normal brain aging (Leuner et al., 2007; Petrosillo et al., 2008). Therefore, the decline of complex I activity correlates with ROS level. Previous studies have suggested that generation of ROS and subsequent ROS-mediated signaling may play an essential role in neuronal cell death induced by mitochondrial complex I inhibition (Gibson \& Huang, 2002; 7, Choi et al., 1999; Choi et al., 2004; 26-27, Petrosillo et al., 2008). We hypothesized therefore that ROS induced by rotenone contributes to the toxic effect of $A \beta$ in the cell death.

To define whether $\mathrm{A} \beta$ increased by overexpressing APPswe and rotenone treatment affects the level of ROS, cells expressing APP-wt, APP-swe or vector control were incubated with rotenone $10 \mu \mathrm{M}$ and stained with dihydroethidium (DHE, a cell-permeable superoxide anion indicator).

A

A
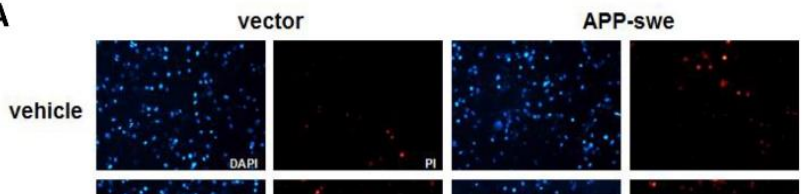

Rot

Rot
$5 \mu \mathrm{M}$
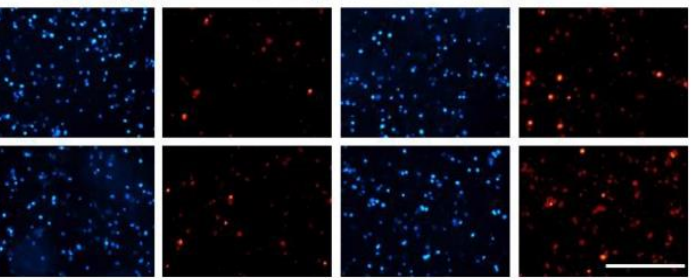

B

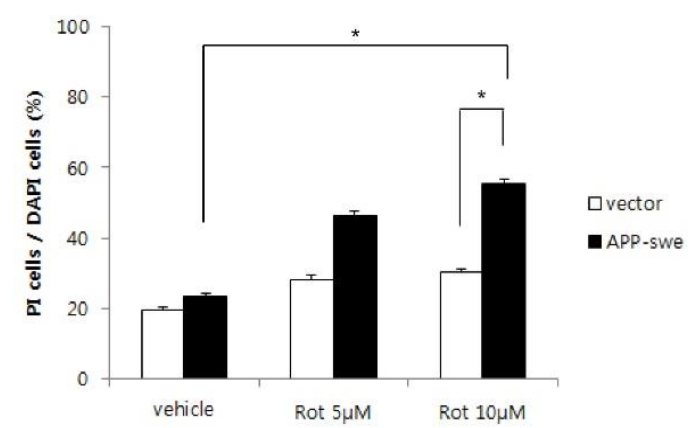

Fig. 2. Cell death was significantly increased by the combination of mitochondrial complex I inhibition and the expression of APP-swe. A. After $18 \mathrm{~h}$ of incubation with rotenone, SH-SY5Y cells were stained with propidium iodide (PI) and DAPI. Representative images were captured using fluorescence microscope. B. The ratio of PI-positive cells to DAPIpositive cells was quantified using Image $J$ software. Cell death was dramatically increased in the cells expressing APP-swe, when treated with rotenone, compared to control. ${ }^{*} P<0.05$. Scale bar, $100 \mu \mathrm{M}$. 
DHE-positive cells were observed using a microscope and superoxide level was measured using microplate reader. As shown in Fig. 3A, expression of APP-wt or APP-swe, by itself, did not increase ROS and rotenone treatment increased ROS level slightly. However, ROS was markedly increased in the cells expressing APP-swe, when they were treated with rotenone (Fig. 3A). Quantitative studies demonstrated that rotenone induces more than 5 times higher

A

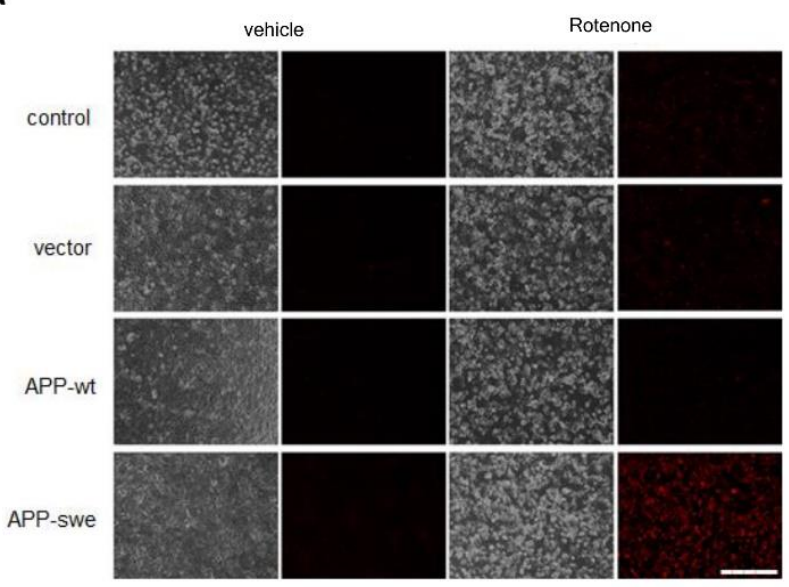

B

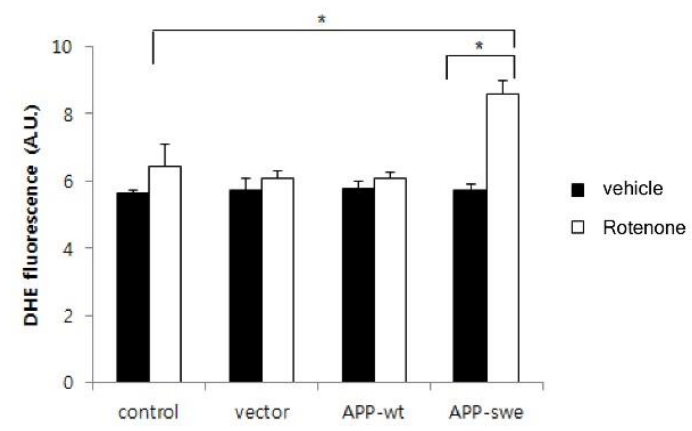

Fig. 3. ROS level was elevated in SH-SY5Y cells expressing APP-swe by treatment with rotenone. A. SH-SY5Y cells expressing APP-wt, APP-swe or vector control were incubated with rotenone $10 \mu \mathrm{M}$ for $24 \mathrm{~h}$ and were stained by dihydroethidium (DHE). Representative images were detected using fluorescent microscope. B. ROS level of cells were measured by microplate reader. DHE fluorescence of APP- swe cells was significantly increased by treatment with rotenone $(10 \mu \mathrm{M}) .{ }^{*} P<0.05$. Scale bar, $100 \mu \mathrm{m}$. increase of ROS in the cells expressing APP-swe than it does in vector control (Fig. 2B).

These results suggest that synergistic effect of mitochondria inhibition and $A \beta$ toxicity on the neuronal cells would be mediated by the elevation of ROS.

\section{DISCUSSION}

We intended to investigate if mitochondrial complex I dysfunction can increase the toxicity of $A \beta$ and affect the biochemical mechanism of A $\beta$ toxicity. First, SH-SY5Y neuroblastoma cells were transfected with DNA harboring the human swedish mutant APP gene, the human wild type APP gene or vector control. A $\beta$ oligomer level was increased by APP-swe overexpression in SH-SY5Y cells. Mild treatment of complex I inhibitor, rotenone (5-20 $\mu \mathrm{M})$, which induces minimum level of cell death, significantly accelerated cell death in the cells transfected with APP-swe. Oxidative stress, demonstrated by oxidation of protein and lipid, is characteristic in AD brain (Varadarajan et al., 2000). $A \beta$ or amyloid plaque binds to metal ions and may mediate generation of ROS. Alternatively, ROS increases $\mathrm{A} \beta$ formation in the brain (Leuner et al., 2012). In this study, our data suggest that generation of ROS induced by dysfunction of mitochondria would be accelerated by $\mathrm{A} \beta$ and synergistic effect on ROS elevation would be the key factor of $\mathrm{AD}$ pathogenesis. This explains why $\mathrm{AD}$ is more common in elderly populations, since mitochondrial defect and $\mathrm{A} \beta$ are increased during aging.

Interestingly, there was no detectable, rotenone-induced difference in cell viability between APP-swe cells and control cells in MTT assay (Fig. 1), although rotenone-induced cell death was significantly increased in the cells expressing APP-swe compared with control, when tested by PI staining (Fig. 2). MTT assay measures NADH dehydrogenase activity and PI stains cells of which the plasma membrane becomes permeable. Considering distinct mechanisms of these two assay we could explain this controversy. 
First, a good portion of PI-positive cells may maintain the activity of NADH dehydrogenase even after membrane permeabilization. Second, rotenone and $A \beta$ may accelerate permeabilization of plasma membrane and generation of ROS but not the eventual cell death transiently. This reminds traditional questions on the validity of cell viability tests and the needs to verify cell viability/death with multiple methods.

As expected, complex I inhibition increased ROS in DHE assay (Fig. 3). ROS produced by complex I inhibitor was synergistically increased by $A \beta$ in cells expressing APPswe. Likewise propidium iodide assay showed dramatic increases of cell death in the cells expressing APP-swe upon treatment of rotenone. This suggests that the combination of $\mathrm{A} \beta$ and complex I dysfunction impairs cell viability by increasing oxidative stress. On the basis of these results, we hypothesized that complex I dysfunction associated with increased ROS production potentiates the toxicity of amyloid cascade in AD. A recent study demonstrated ROS increases $A \beta$ formation in the brain, supporting our hypothesis (Leuner et al., 2012). Further study would be needed to elucidate detailed mechanisms involving these combinational effect of mitochondrial defect, $A \beta$ and ROS in $A D$.

Our results support the idea that the complex I dysfunction increases ROS level and increased ROS level leads to the increase of $A \beta$ level and toxicity. Potentiation of $A \beta$ toxicity may accelerate mitochondria dysfunction, in turn. Based on these results, we suggest complex I dysfunction could be the starting point of the amyloid cascade in sporadic $\mathrm{AD}$, in which the pathogenesis is accelerated by a vicious cycle between complex I dysfunction and $A \beta$ toxicity.

\section{ACKNOWLEDGMENTS}

This study was financially supported by Chonnam National University, 2016.

\section{REFERENCES}

Choi WS, Eom DS, Han BS, Kim WK, Han BH, Choi EJ, Oh TH, Markelonis GJ, Cho JW, Oh YJ (2004) Phosphorylation of p38 MAPK induced by oxidative stress is linked to activation of both caspase-8- and -9-mediated apoptotic pathways in dopaminergic neurons. J Biol Chem 279(19):20451-60.

Choi WS, Yoon SY, Oh TH, Choi EJ, O'Malley KL, Oh YJ (1999) Two distinct mechanisms are involved in 6-hydroxydopamine- and $\mathrm{MPP}^{+}$-induced dopaminergic neuronal cell death: role of caspases, ROS, and JNK. J Neurosci Res 57:86-94.

Devi L, Prabhu BM, Galati DF, Avadhani NG, Anandatheerthavarada HK (2006) Accumulation of amyloid precursor protein in the mitochondrial import channels of human Alzheimer's disease brain is associated with mitochondrial dysfunction. J Neurosci 26:9057-9068.

Eckert A, Keil U, Marques CA, Bonert A, Frey C, Schussel K, Muller WE (2003) Mitochondrial dysfunction, apoptotic cell death, and Alzheimer's disease. Biochem Pharmacol 66:1627-1634.

Fernandez-Vizarra P, Fernandez AP, Castro-Blanco S, Serrano J, Bentura ML, Martinez-Murillo R, Martinez A, Rodrigo J (2004) Intra- and extracellular Abeta and PHF in clinically evaluated cases of Alzheimer's disease. Histol Histopathol 19:823-844.

Gandy S (2005) The role of cerebral amyloid $\beta$ accumulation in common forms of Alzheimer disease. J Clin Invest 115:1121-1129.

Gibson GE, Huang HM (2002) Oxidative processes in the brain and non-neuronal tissues as biomarkers of Alzheimer's disease. Front Biosci 7:d1007-d1015.

Haass C, Selkoe DJ (2007) Soluble protein oligomers in neurodegeneration: lessons from the Alzheimer's amyloid betapeptide. Nat Rev Mol Cell Biol 8:101-112.

Kushnareva Y, Murphy AN, Andreyev A (2002) Complex I-mediated reactive oxygen species generation: modu- 
lation by cytochrome $\mathrm{c}$ and $\mathrm{NAD}[\mathrm{P}]^{+}$oxidation-reduction state. Biochem J 368:545-553.

Lecoeur H (2002) Nuclear apoptosis detection by flow cytometry: Influence of endogenous endonucleases. Exp. Cell Res 277:1-14.

Leuner K, Hauptmann S, Abdel-Kader R, Scherping I, Keil U, Strosznajder JB, Eckert A, Muller WE (2007) Mitochondrial dysfunction: The first domino in brain aging and Alzheimer's disease? Antioxid Redox Signal 9: 1659-1675.

Leuner K, Muller WE et al. (2012) Mitochondrion-derived reactive oxygen species lead to enhanced amyloid beta formation. Antioxid Redox Signal 16:1421-1433.

Lustbader JW, Cirilli M, Lin C, Xu HW, Takuma K, Wang N, Caspersen C, Chen X, Pollak S, Chaney M, Trinchese F, Liu S, Gunn-Moore F, Lue LF, Walker DG, Kuppusamy P, Zewier ZL, Arancio O, Stern D, Yan SS, Wu $\mathrm{H}$ (2004) ABAD directly links Abeta to mitochondrial toxicity in Alzheimer's disease. Science 304:448-452.

Manczak M, Jung Y, Park BS, Partovi D, Reddy PH (2005) Time-course of mitochondrial gene expressions in mice brains: implications for mitochondrial dysfunction, oxidative damage, and cytochrome $\mathrm{c}$ in aging. J Neurochem 92:494-504.

Mattson MP, Liu D (2002) Energetics and oxidative stress in synaptic plasticity and neurodegenerative disorders. Neuromolecular Med 2:215-231.

Mattson MP (2007) Mitochondrial regulation of neuronal plasticity. Neurochem Res 32:707-715.

Mattson MP, Gleichmann M, Cheng A (2008) Mitochondria in neuroplasticity and neurological disorders. Neuron 60:748-766.

Maurer I, Zierz S, Möller HJ (2002) A selective defect of cytochrome $\mathrm{c}$ oxidase is present in brain of Alzheimer disease patients. Neurobiol Aging 21:455-462.

Paradies G, Petrosillo G, Paradies V, Ruggiero FM (2010) Oxidative stress, mitochondrial bioenergetics, and cardiolipin in aging. Free Radic Biol Med 48: 1286-1295.
Parker WD Jr, Filley CM, Parks JK (1990) Cytochrome oxidase deficiency in Alzheimer's disease. Neurology 40:1302-1303.

Pavlov PF, Hansson Petersen C, Glaser E, Ankarcrona M (2009) Mitochondrial accumulation of APP and Abeta: significance for Alzheimer disease pathogenesis. J Cell Mol Med 13:4137-4145.

Petrosillo G, Matera M, Casanova G, Ruggiero FM, Paradies G (2008) Mitochondrial dysfunction in rat brain with aging Involvement of complex I, reactive oxygen species and cardiolipin. Neurochem Int 53: 126-131.

Querfurth HW, LaFerla FM (2010) Alzheimer's disease. N Engl J Med 362: 329-344.

Reddy PH, Beal MF (2008) Amyloid beta, mitochondrial dysfunction and synaptic damage: implications for cognitive decline in aging and Alzheimer's disease. Trends Mol Med 4:45-53.

Reddy PH (2009a) The role of mitochondria in neurodegenerative diseases: mitochondria as a therapeutic target in Alzheimer's disease. CNS Spectr 14:8-18.

Reddy PH (2009b) Amyloid beta, mitochondrial structural and functional dynamics in Alzheimer's disease. Exp Neurol 218:286-292.

Rhein V, Eckert A (2007) Effects of Alzheimer's amyloidbeta and tau protein on mitochondrial function-role of glucose metabolism and insulin signalling. Arch Physiol Biochem 113:131-141.

Selkoe DJ (1999) Translating cell biology into therapeutic advances in Alzheimer's disease. Nature 399:A23-31.

Smith MA, Perry G, Richey PL, Sayre LM, Anderson VE, Beal MF, Kowall N (1996) Oxidative damage in Alzheimer's. Nature 382:120-121.

Varadarajan S, Yatin S, Aksenova M, Butterfield DA (2000) Review: Alzheimer's amyloid $\beta$-peptide-associated free radical oxidative stress and neurotoxicity. J Struct Biol. 130:184-208.

Zhang YW, Thompson R, Zhang H, Xu H (2011) APP processing in Alzheimer's disease. Mol Brain 4:3. 